\title{
Frações lábeis e recalcitrantes da matéria orgânica em solos sob integração lavoura-pecuária
}

\author{
Eulene Francisco da Silva(1), Elaine Pinheiro Reis Lourente(2), Marlene Estevão Marchetti(2), \\ Fábio Martins Mercante ${ }^{(3)}$, Ana Karolina Teixeira Ferreira ${ }^{(2)}$ e Gisele Carneiro Fujii( ${ }^{(2)}$
}

\begin{abstract}
(1)Universidade Federal Rural do Semi Árido, Departamento de Ciências Ambientais e Tecnológicas. Avenida Francisco Mota, no 572 , Bairro Costa e Silva, CEP 59625-900 Mossoró, RN. E-mail: eulenesilva@ufersa.edu.br (2)Universidade Federal da Grande Dourados, Faculdade de Ciências Agrárias, Rodovia Dourados-Itahum Km 12, Caixa Postal 533, CEP 79804-970 Dourados, MS. E-mail: elainelourente@ufgd.edu.br,

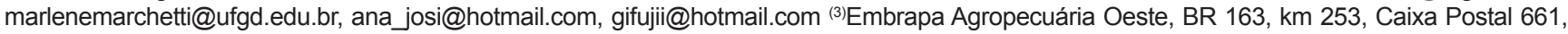
CEP 79804-970 Dourados, MS. E-mail: mercante@cpao.embrapa.br
\end{abstract}

Resumo - O objetivo deste trabalho foi avaliar o estoque de carbono orgânico total (COT) e nitrogênio total (NT), C e N nas frações lábeis e recalcitrantes da matéria orgânica do solo (MOS) e o índice de manejo de C, em solos sob sistema de integração lavoura-pecuária (ILP), após quatro (ILP4) e oito anos (ILP8) de implantação. Para comparação, foram utilizados outros sistemas de manejo: pastagem e lavoura em plantio direto (PD), além de vegetação nativa. $\mathrm{O}$ experimento foi realizado em delineamento inteiramente casualizado, com cinco repetições. A integração lavoura-pecuária, estabelecida num período de oito anos, é capaz de alcançar um novo estado estável equivalente ao sistema sob plantio direto com 23 anos de implantação. Houve acúmulo no estoque de $\mathrm{C}$ total de 101,0 (ILP8) e 104,2 $\mathrm{Mg} \mathrm{ha}^{-1}$ (PD) e $\mathrm{N}$ total de 5,5 (ILP8) e 5,8 $\mathrm{Mg} \mathrm{ha}^{-1}$ (PD), na camada 0-30 cm, bem como aumento no estoque de $\mathrm{C}$ e $\mathrm{N}$ nas frações lábeis e recalcitrantes da MOS. Para o ILP com oito anos, o índice de manejo de $\mathrm{C}$ de 88 foi superior ao dos demais sistemas de manejo e não diferiu da vegetação nativa na camada $0-10 \mathrm{~cm}$, todavia, foi similar ao PD na análise de todo o perfil $(0-30 \mathrm{~cm})$.

Termos para indexação: carbono orgânico, índice de manejo de carbono, nitrogênio, substâncias húmicas.

\section{Labile and recalcitrant fractions of soil organic matter under integrated crop-livestock system}

\begin{abstract}
The objective of this work was to evaluate the soil total organic carbon (TOC) and total nitrogen (TN) stocks, $\mathrm{C}$ and $\mathrm{N}$ in labile and recalcitrant fractions of the soil organic matter (SOM), and the $\mathrm{C}$ management index, in soils under integrated crop-livestock (ICL) system after four (ICL4) and eight years (ICL8) of settlement. For comparison purposes, other management systems were used: pasture and crop under no tillage (NT), besides native vegetation. The experiment was carried out in a completely randomized block design, with five replicates. The crop-livestock established in a period of eight years can reach a new steady state equivalent to the no-tillage with 23 years of implementation. There was accumulation in total organic carbon of 101.0 (ICL8) and 104.2 $\mathrm{Mg} \mathrm{ha}^{-1}$ (NT), and $\mathrm{N}$ total stock of 5.5 (ICL8) and $5.8 \mathrm{Mg} \mathrm{ha}^{-1}$ (NT) in the 0-30 cm layer, as well as increase in the stock of labile and recalcitrant $\mathrm{C}$ and $\mathrm{N}$ fractions of SOM. For crop-livestock with eight years, the $\mathrm{C}$ management index of 88 was higher than other management systems, and not different from native vegetation $(0-10 \mathrm{~cm})$, however, it was similar to NT in the analysis of the entire profile $(0-30 \mathrm{~cm})$.
\end{abstract}

Index terms: organic carbon, carbon management index, nitrogen, humic substances.

\section{Introdução}

$\mathrm{Na}$ tentativa de equilibrar a produtividade agrícola com a conservação do meio ambiente e favorecer o incremento nos teores de $\mathrm{C}$, nas últimas décadas, têm-se desenvolvido novos conceitos agrícolas com base na conservação do solo, na ciclagem de nutrientes e na diversificação de culturas. Sistemas que englobam o uso de gramíneas têm-se destacado, como a integração lavoura-pecuária (ILP) e o plantio direto (PD), que são capazes de manter ou até mesmo elevar os teores de matéria orgânica do solo (MOS) nas camadas superficiais (Diekow et al., 2005; Loss et al., 2009; Souza et al., 2009; Batlle-Bayer et al., 2010). Alterações na MOS influenciam diretamente a conservação do meio ambiente, pois afetam a infiltração, retenção de água, susceptibilidade à erosão, complexação de elementos tóxicos e estruturação do solo (Conceição et al., 2005).

Pesq. agropec. bras., Brasília, v.46, n.10, p.1321-1331, out. 2011 
Cerca de $60 \%$ do território do Mato Grosso do Sul é ocupado por área de Cerrado, onde as temperaturas e os índices pluviométricos elevados favorecem a decomposição dos resíduos culturais. Uma das alternativas de manutenção da MOS é a utilização de plantas de cobertura, com elevada produção de resíduos e que apresentem maior tempo de meia-vida, o que resulta em menor velocidade de decomposição e mantém os resíduos vegetais sobre o solo por maior tempo (Ceretta et al., 2002; Rossi, 2009). O sistema ILP, que inclui gramíneas do gênero Urochloa spp. (Syn. Brachiaria spp.), é eficiente em acumular C, em comparação aos demais sistemas de manejo, pois é favorecido pelo sistema radicular abundante, volumoso, de contínua renovação e elevado efeito rizosférico da gramínea (D’Andréa et al., 2004). Segundo Nicoloso et al. (2008), o solo sob ILP tem potencial para ser um dreno de $\mathrm{C}$ atmosférico e favorecer o acúmulo da MOS.

A maioria dos estudos concentra-se no $\mathrm{C}$ orgânico total (COT) e N total (NT), todavia, pequenas alterações nos totais de $\mathrm{C}$ e $\mathrm{N}$ são dificilmente detectáveis em curto prazo, em parte porque a variabilidade natural do solo é elevada. Assim, o declínio ou acréscimo de C, nas frações da MOS, pode permitir a mensuração do grau de preservação dos ecossistemas naturais e os possíveis impactos causados em sistemas agrícolas com diferentes tipos de manejo do solo.

A fração lábil apresenta alta taxa de decomposição e um curto período de permanência no solo, e sua principal função é o fornecimento de nutrientes às plantas pela mineralização, além de energia e $\mathrm{C}$ aos microrganismos do solo (Silva \& Mendonça, 2007). A fração humificada representa cerca de $2 / 3$ do C orgânico e tem maior permanência no solo, sua principal função é atuar sobre as condições físicas e químicas do solo, além de ser importante no sequestro de C atmosférico (Silva \& Mendonça, 2007). A alternativa para analisar a dinâmica da MOS é a utilização do índice de manejo de carbono (IMC), sugerido por Blair et al. (1995) e Vieira et al. (2007), que leva em consideração aspectos da labilidade da MOS e permite comparar as mudanças que ocorrem no $\mathrm{C}$ orgânico total e no $\mathrm{C}$ lábil, em consequência do uso e manejo do solo. O fato de os sistemas de manejo mostrarem IMC superior ou igual ao da mata nativa (100), que representa o sistema de referência, evidencia a capacidade desses sistemas de melhorar a qualidade do solo e promover a sustentabilidade do agroecossistema em regiões tropicais. Valores de IMC inferiores a 100 são indicativos de impacto negativo das práticas de manejo sobre os teores da MOS (Blair et al., 1995).

A qualidade e a quantidade de COT têm sido sugeridas como importantes fatores que afetam a dinâmica do $\mathrm{N}$ no solo (Hart et al., 1994) e a retenção de N no ecossistema, os quais devem ser estudados em conjunto. Além disso, solos degradados pelo cultivo e com baixos teores de COT, normalmente, são deficientes em N, o que limita a adição de $\mathrm{C}$, principalmente, em sistemas constituídos por gramíneas (Lovato et al., 2004).

$\mathrm{O}$ objetivo deste trabalho foi avaliar o estoque de $\mathrm{C}$ e $\mathrm{N}$ totais, $\mathrm{C}$ e $\mathrm{N}$ nas frações lábeis e recalcitrantes da MOS e o IMC, em sistema ILP, após quatro e oito anos de implantação, comparado com diversos sistemas de manejo, tais como pastagem e PD, além de mata nativa.

\section{Material e Métodos}

O experimento foi realizado em Maracaju, MS, a $21^{\circ} 36^{\prime} 52^{\prime \prime} \mathrm{S}, 55^{\circ} 10^{\prime} 06^{\prime \prime} \mathrm{W}$, e altitude de $384 \mathrm{~m}$, no mês de junho de 2009. O clima é caracterizado como Cwa, conforme Köppen (Ayoade, 1986), com precipitação média anual de $1.500 \mathrm{~mm}$ e temperatura média anual de $22^{\circ} \mathrm{C}$. A pesquisa foi realizada em sistemas produtivos explorados comercialmente e conduzidos em propriedades rurais particulares.

Foram avaliados dois sistemas ILP, implantados em áreas adjacentes; o primeiro estabelecido há oito anos, e o segundo, há quatro anos. A área ocupada pelo ILP, estabelecido há oito anos, foi cultivada por 19 anos com diferentes culturas agrícolas em PD. Há oito anos, foi introduzida a pecuária, onde as pastagens eram rotacionadas com lavoura, a cada quatro anos (quatro de lavoura e quatro de pastagens). A sequência de culturas, utilizadas na safra de verão, foi soja/algodão/ soja/pastagem e, no inverno, capim-pé-de-galinha (Eleusine coracana L.)/aveia-preta (Avena sativa L.) + capim-tanzânia (Panicum maximum)/milho (segunda safra)+capim-tanzânia+braquiária (Urochloa decumbens (Stapf) R.D.Webster)/pastagem. A amostragem de solo para as avaliações foi realizada durante o cultivo de Urochloa brizantha (Hochst. ex A. Rich.) R.D. Webster. O manejo da pastagem foi realizado por meio do rodízio do gado em talhões de 50 ha, com o período de pastejo de aproximadamente 16 meses, sendo a área constituída de 12 talhões de 50 ha. A taxa de lotação inicial foi de 2,98 unidade animal (UA) 
por hectare e, no final do período de engorda, foi de 5,1 UA ha ${ }^{-1}$.

O segundo sistema ILP, localizado a $1.200 \mathrm{~m}$ do primeiro ILP, foi estabelecido há quatro anos, em área cultivada por 15 anos com diferentes culturas agrícolas, também em PD, com a mesma sequência de culturas (rotação) e o mesmo manejo do ILP estabelecido há oito anos. A amostragem de solo para as avaliações também foi realizada durante o cultivo de $U$. brizantha.

Os sistemas utilizados para comparação incluíram as áreas descritas a seguir. A primeira foi uma área localizada à distância de 400 m, ocupada com pastagem (pastagem revolvida), estabelecida há 25 anos com braquiária ( $U$. decumbens), com calagem e adubação apenas em sua implantação, e utilização de $0,8 \mathrm{UA} \mathrm{ha}^{-1}$ por ano. Essa área apresentava sinais de degradação, com exposição do solo, consequência da escassa cobertura vegetal, com alta infestação de plantas daninhas e de espécies arbustivas. A área foi revolvida em 2009, com duas arações e uma gradagem, tendo sido aplicados $800 \mathrm{~kg} \mathrm{ha}^{-1}$ de gesso agrícola e $4 \mathrm{Mg} \mathrm{ha}^{-1}$ de calcário dolomítico. A coleta foi realizada após as operações de preparo do solo e antes da semeadura de soja. A segunda área, localizada a $1.200 \mathrm{~m}$ (em frente ao ILP com quatro anos), foi ocupada com lavoura em PD por 23 anos, cultivada com soja no verão, e milho no inverno (segunda safra). Esporadicamente, era cultivada aveia no inverno, e não se utilizou outra prática para formação de palhada. A terceira área continha vegetação natural (mata nativa), caracterizada como área de reserva, sem ação antrópica, utilizada como ecossistema de referência da região, que estava separada à distância máxima de $3.000 \mathrm{~m}$.

Em todos os sistemas de uso, os solos foram classificados como Latossolo Vermelho distroférrico, textura argilosa, compostos na fração argila principalmente por óxidos e hidróxidos de Fe e Al. As características físicas e químicas foram analisadas conforme Claessen (1997) e se encontram nas Tabelas $1 \mathrm{e} 2$.

Foram selecionados talhões de 5 ha, de cada área selecionada, e cada talhão foi considerado uma parcela, em se que coletaram amostras de solo das profundidades de $0-10,10-20,20-30 \mathrm{~cm}$. Em cada ponto de amostragem (cinco pontos por talhão), com cinco repetições, foram abertas trincheiras de $35 \times 35 \times 50 \mathrm{~cm}$ de largura, comprimento e profundidade, respectivamente.

A determinação do $\mathrm{C}$ orgânico foi realizada pelo método de oxidação por via úmida, com aquecimento externo, proposto por Yeomans \& Bremner (1988), e o $\mathrm{N}$ foi determinado pelo método de destilação de Kjeldhal. Para a determinação de $\mathrm{C}$ e $\mathrm{N}$ das frações recalcitrantes, as amostras de terra fina seca ao ar foram trituradas, passadas em peneira de 60 mesh $(0,210 \mathrm{~mm})$ e submetidas ao fracionamento de substâncias húmicas,

Tabela 1. Valores de $\mathrm{pH}$, fósforo disponível, cátions trocáveis $\left(\mathrm{K}^{+}, \mathrm{Ca}^{2+} \mathrm{e} \mathrm{Mg}^{2+}\right)$, acidez potencial $(\mathrm{H}+\mathrm{Al})$, soma de bases (SB), capacidade de troca de cátions potencial ( $\mathrm{T}$ ) e saturação por bases (V\%), para as diferentes profundidades do solo com diferentes manejos ${ }^{(1)}$.

\begin{tabular}{|c|c|c|c|c|c|c|c|c|c|c|c|}
\hline Manejo & Camada & $\mathrm{pH}$ & $P$ & $\mathrm{~K}^{+}$ & $\mathrm{Al}^{3+}$ & $\mathrm{Ca}^{2+}$ & $\mathrm{Mg}^{2+}$ & $\mathrm{H}+\mathrm{Al}$ & SB & $\mathrm{T}$ & $\mathrm{V}$ \\
\hline do solo & $(\mathrm{cm})$ & $\mathrm{H}_{2} \mathrm{O}$ & $\left(\mathrm{mg} \mathrm{dm} \mathrm{m}^{-3}\right)$ & -----. & ----- & ----- ( & $\left.1_{\mathrm{c}} \mathrm{dm}^{-3}\right)$ & -------- & ------- & ---- & $(\%)$ \\
\hline \multirow{3}{*}{$\mathrm{VN}$} & $0-10$ & 5,3 & 4,6 & 10,3 & 2,3 & 56,6 & 24,5 & 85,6 & 91,6 & 177,2 & 51,9 \\
\hline & $10-20$ & 4,7 & 2,1 & 4,5 & 12,3 & 18,1 & 10,7 & 131,7 & 33,3 & 164,9 & 21,2 \\
\hline & $20-30$ & 4,6 & 1,4 & 2,8 & 18,9 & 5,8 & 6,5 & 132,6 & 15,1 & 147,7 & 10,8 \\
\hline \multirow{3}{*}{ PD } & $0-10$ & 5,7 & 37,1 & 15,8 & 0,5 & 44,5 & 14,8 & 55,2 & 75,1 & 130,3 & 57,6 \\
\hline & 10-20 & 5,1 & 6,8 & 6,8 & 1,3 & 23,3 & 7,0 & 75,4 & 37,0 & 112,4 & 33,2 \\
\hline & $20-30$ & 5,1 & 3,9 & 5,3 & 1,1 & 25,3 & 7,5 & 66,3 & 38,0 & 104,3 & 37,8 \\
\hline \multirow{3}{*}{ PR } & $0-10$ & 5,7 & 12,2 & 3,8 & 1,6 & 49,5 & 13,0 & 54,6 & 66,3 & 120,9 & 54,8 \\
\hline & $10-20$ & 5,1 & 1,4 & 2,5 & 9,5 & 16,3 & 3,4 & 87,4 & 22,2 & 109,6 & 21,3 \\
\hline & $20-30$ & 5,0 & 1,1 & 1,3 & 13,7 & 12,3 & 2,2 & 90,5 & 15,7 & 106,2 & 14,8 \\
\hline \multirow{3}{*}{ ILP4 } & $0-10$ & 6,0 & 22,7 & 17,1 & 1,5 & 46,5 & 20,3 & 58,9 & 83,8 & 142,8 & 58,8 \\
\hline & $10-20$ & 5,5 & 5,0 & 4,3 & 2,0 & 24,8 & 10,4 & 69,2 & 39,4 & 108,6 & 37,9 \\
\hline & 20-30 & 5,3 & 2,2 & 2,6 & 1,4 & 17,8 & 7,5 & 56,2 & 27,9 & 84,1 & 33,3 \\
\hline \multirow{3}{*}{ ILP8 } & $0-10$ & 6,1 & 57,3 & 38,2 & 0,8 & 49,8 & 22,0 & 43,3 & 109,9 & 153,2 & 71,6 \\
\hline & 10-20 & 4,9 & 12,5 & 10,3 & 6,0 & 15,8 & 7,5 & 86,6 & 33,6 & 120,2 & 28,2 \\
\hline & $20-30$ & 4,9 & 4,1 & 8,1 & 5,1 & 14,8 & 7,0 & 63,0 & 29,8 & 92,8 & 32,4 \\
\hline
\end{tabular}

(1) $\mathrm{pH}$ em água, relação 1:2,5; P, extrator Mehlich 1, extrator $\mathrm{KCl}-1$ mol L-1. VN, vegetação nativa; PD, plantio direto; PR, pastagem revolvida; ILP4, sistema de integração lavoura-pecuária implementado há quatro anos; ILP8, sistema de integração lavoura-pecuária implementado há oito anos. 
segundo o método da International Humic Substances Society (IHSS) (Swift, 2001). Desse fracionamento, foram obtidas as frações correspondentes aos ácidos fúlvicos, ácidos húmicos e huminas, pela solubilidade diferencial em soluções ácidas e alcalinas. Do somatório de todas essas frações húmicas, foram obtidas as substâncias húmicas e foram determinados $\mathrm{C}$ e $\mathrm{N}$, conforme descrito anteriormente.

Para a determinação do teor de $\mathrm{C}$ e $\mathrm{N}$ lábeis $(\mathrm{CL}$ e NL), subamostras de $1,0 \mathrm{~g}$ de solo (camada de 0-20 cm) foram trituradas, passadas em peneira de $0,210 \mathrm{~mm}$ e acondicionadas em tubo de centrífuga de $50 \mathrm{~mL}$, juntamente com $25 \mathrm{~mL}$ de solução de $\mathrm{KMnO}_{4}\left(0,033 \mathrm{~mol} \mathrm{~L}^{-1}\right)$ (Shang \& Tiessen, 1997). Os tubos foram colocados em agitador horizontal a $170 \mathrm{rpm}$, por 1 hora, e centrifugados a $960 \mathrm{~g}$, por $10 \mathrm{~min}$, sempre protegidos da luz. Após centrifugação, colocaram-se $100 \mu \mathrm{L}$ do sobrenadante em tubos de ensaio e o volume foi completado com $10 \mathrm{~mL}$ com água deionizada. As dosagens do CL foram realizadas em espectrofotômetro, com comprimento de onda de $565 \mathrm{~nm}$, e as do NL foram reduzidas com adição de $10 \mathrm{~mL}$ do extrato em tubo de digestão e determinadas pelo método de destilação Kjeldhal, sem a etapa da digestão. $\mathrm{O}$ carbono não lábil (CNL) foi determinado pela diferença entre o COT e o CL.

Com base nas mudanças no COT, entre um sistema de referência (vegetação nativa) e um sistema cultivado, foi calculado o índice de compartimento de carbono (ICC), calculado como: $\mathrm{ICC}=\mathrm{COT}$ cultivado/COT referência. Com base nas mudanças na proporção de CL (labilidade $=\mathrm{CL} / \mathrm{CNL}$ ) no solo, calculou-se o índice de labilidade (IL) por IL = L cultivado/L referência. Estes dois índices foram usados para calcular o índice

Tabela 2. Médias \pm desvio-padrão da análise granulométrica de Latossolo Vermelho distróferrico sob os diferentes sistemas de manejo do solo ${ }^{(1)}$.

\begin{tabular}{|c|c|c|c|}
\hline Manejo do solo & Areia & Silte & Argila \\
\hline & -------------- & $\left(\mathrm{g} \mathrm{kg}^{-1}\right)$ & ----- \\
\hline $\mathrm{VN}$ & $234,4 \pm 0,53$ & $81,9 \pm 2,78$ & $683,7 \pm 2,83$ \\
\hline PD & $185,7 \pm 0,37$ & $96,5 \pm 1,53$ & $717,7 \pm 1,89$ \\
\hline PR & $169,3 \pm 0,39$ & $101,9 \pm 3,09$ & $728,7 \pm 2,74$ \\
\hline ILP4 & $206,0 \pm 0,28$ & $77,9 \pm 0,73$ & $716,1 \pm 0,65$ \\
\hline ILP8 & $226,6 \pm 0,49$ & $64,2 \pm 0,72$ & $709,2 \pm 0,34$ \\
\hline
\end{tabular}

${ }^{(1)} \mathrm{VN}$, vegetação nativa; PD, plantio direto; PR, pastagem revolvida; ILP4, sistema de integração lavoura-pecuária implementado há quatro anos; ILP8, sistema de integração lavoura-pecuária implementado há oito anos. de manejo de carbono (IMC), obtido pela expressão $\mathrm{IMC}=\mathrm{ICC} \times \mathrm{IL} \times 100$ (Blair et al., 1995).

Os estoques de $\mathrm{C}$ foram obtidos pela massa equivalente de solos (Ellert \& Bettany, 1995), tendo como referência a área da vegetação nativa (VN). Os estoques foram calculados, tendo-se subtraído o conteúdo de $\mathrm{C}$ da massa extra de solo da camada mais profunda (20-30 cm) (Ellert \& Bettany, 1995). A densidade do solo $\left(\mathrm{kg} \mathrm{dm}^{-3}\right)$ foi determinada pelo método do anel volumétrico, conforme Claessen (1997), nas camadas de 0-10, 10-20 e 20-30 cm de solo.

O experimento foi realizado em delineamento inteiramente casualizado, com cinco repetições. Os resultados foram submetidos à análise de variância, e as médias dos tratamentos foram submetidas ao teste $\mathrm{t}$, a $5 \%$ de probabilidade, com utilização do programa estatístico SAEG 9.0.

\section{Resultados e Discussão}

Houve variação nos teores de carbono (COT) e nitrogênio total (NT), entre os sistemas de manejos do solo, independentemente da camada considerada (Figura 1). O sistema ILP, propiciou estoque de COT semelhante ao do sistema sob plantio direto (PD), todavia, obteve menor teor de $\mathrm{C}$ em comparação ao sistema sob a vegetação nativa (VN) nas três camadas estudadas.

Os sistemas conservacionistas de manejo como o ILP, com oito e quatro anos, apresentaram teores de C semelhantes aos do PD com 23 anos de implantação, nas camadas $0-10,10-20$ e $20-30 \mathrm{~cm}$. O estoque de C acumulado na camada de $0-30 \mathrm{~cm}$ foi semelhante nos sistemas de manejo PD, ILP4 e ILP8, e menor que o da vegetação nativa (Figura 1). A conversão de áreas de vegetação nativa em cultivo agrícola e florestal, geralmente resulta na diminuição de 20 a 50\% dos teores de COT (Lal et al., 2005).

O fato de os sistemas de integração lavoura-pecuária apresentarem quantidades de COT semelhantes às do sistema de PD estabelecido há 23 anos, provavelmente, ocorreu pelo maior aporte e menor fragmentação de resíduos orgânicos, o que causou a diminuição da decomposição pelos microganismos. A alternância de cultivos de plantas de famílias diferentes nessas áreas, proporcionou melhor aproveitamento e exploração do solo. Assim, as gramíneas, especialmente a braquiária, mostraram-se eficientes no acúmulo de $\mathrm{C}$, pelo seu 
sistema radicular abundante e volumoso, que apresenta contínua renovação e elevado efeito rizosférico (D’Andréa et al., 2004).

Os incrementos nos teores de COT foram maiores na camada superficial (Figura 1). Esses dados corroboram
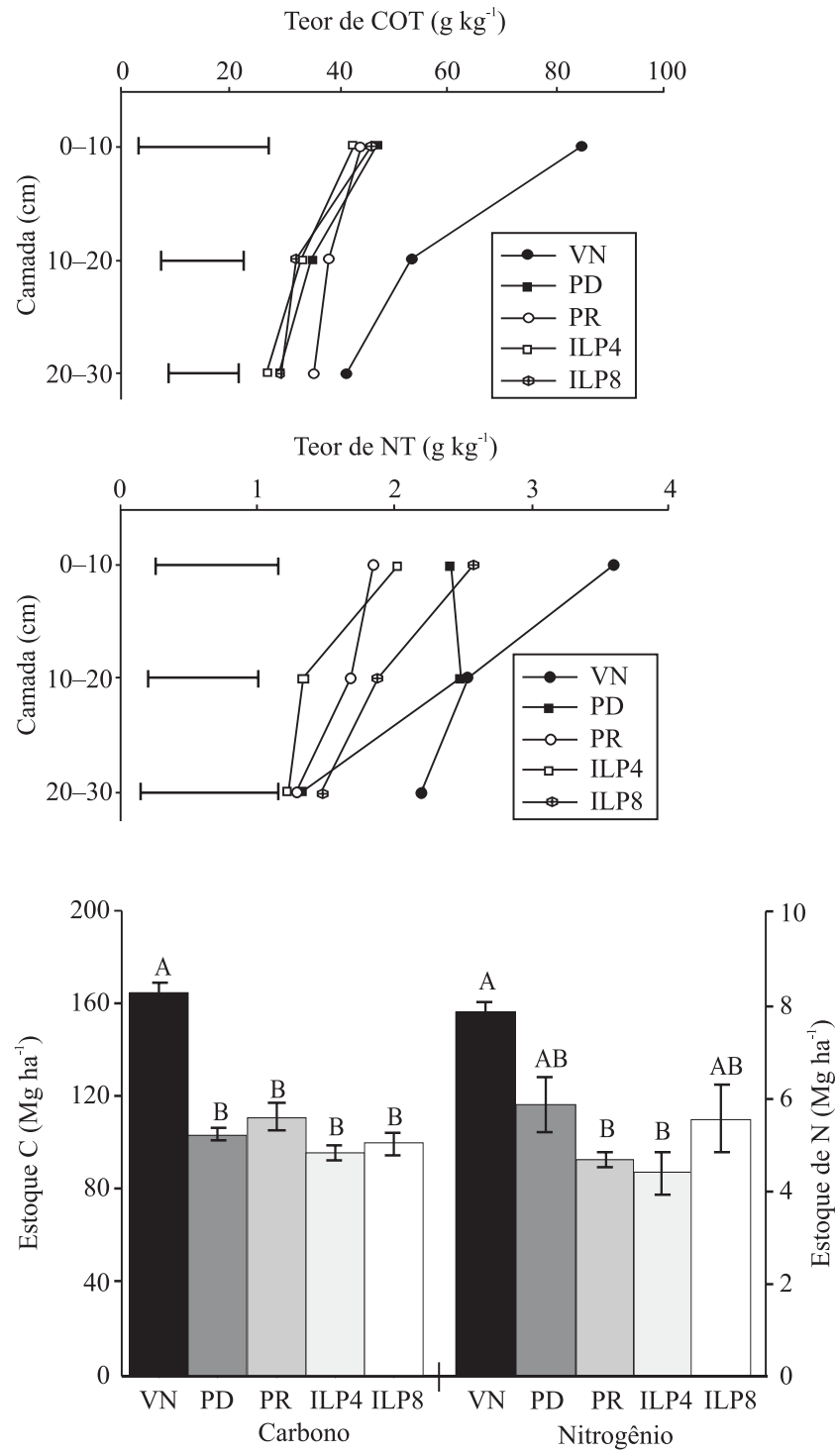

Figura 1. Teor de carbono orgânico (COT) e nitrogênio total (NT), em sistemas de manejo do solo, nas camadas 0-10, 10-20 e 20-30 cm de profundidade, e seus estoques no perfil do solo. VN, vegetação nativa; PD, plantio direto; PR, pastagem revolvida; ILP4 e ILP8, sistema de integração lavoura-pecuária, após quatro e oito anos de implantação. Médias seguidas de letras iguais não diferem entre si, pelo teste $\mathrm{t}$ a $5 \%$ de probabilidade. Barras horizontais referemse à DMS pelo teste $\mathrm{t}$ e barras verticais referem-se ao erropadrão da média. os de Santos et al. (2009), que analisaram seis sistemas ILP com diferentes rotações de culturas no Rio Grande do Sul, em Latossolo Vermelho distrófico típico, e verificaram que em todos os sistemas ILP houve acúmulo de COT nas camadas próximas à superfície do solo, que é a que tem maior concentração de raízes. Os autores também verificaram que, após oito anos de implantação, a MOS no ILP e no PD não diferiram da VN, e apontaram a eficiência destes sistemas em acumular $\mathrm{C}$, conforme já constatado por Bayer et al. (2000), Ciotta et al. (2002) e Sisti et al. (2004). D’Andréia et al. (2004) observaram que modelos de produção de grãos com lavoura + pastagem, em plantio direto, foram promissores para aumentar os estoques de $\mathrm{C}$ do solo, em comparação ao cerrado nativo e à lavoura em preparo convencional de solo.

Os solos de todos os sistemas de manejo utilizados nesses estudos, são classificados como Latossolo Vermelho distroférrico de textura argilosa, com elevados teores de óxidos e hidróxidos de $\mathrm{Fe}$ e $\mathrm{Al}$, fato que contribuiu para aumentar a estabilidade da MOS, em razão da alta capacidade de proteção na forma de complexos organo-minerais (Roscoe \& Buurman, 2003). O maior aporte de resíduo em superfície e o revolvimento somente na linha de plantio promoveram um aumento do estoque de COT, principalmente nos primeiros centímetros do solo. Em Latossolo Vermelho distroférrico, cultivado em plantio direto com uso de pastagem por dez anos, Souza et al. (2009) observaram elevados teores de $\mathrm{C}$ e $\mathrm{N}$ e atribuíram isso à proteção da MOS, pela quantidade de argila e pelos minerais presentes nesta fração, representados em sua maioria por óxidos de $\mathrm{Fe}$ e Al, além da agregação do solo.

Os sistemas de manejo considerados mais conservacionistas, como o ILP 8 e o PD, propiciaram teores de NT semelhantes aos da VN e mais elevados que os dos demais sistemas de manejo somente na camada de 0-10 cm (Figura 1). Os estoques de NT $(0-30 \mathrm{~cm})$ para o ILP8 e PD foram de 5,5 e 5,8 Mg $\mathrm{ha}^{-1}$ de $\mathrm{N}$, respectivamente. O cultivo de leguminosas e gramíneas em rotação adicionaram $\mathrm{N}$ ao solo, por meio da fixação biológica de nitrogênio (FBN), o que constitui importante contribuição deste nutriente ao sistema de rotação. Resultados obtidos por Lovato et al. (2004) confirmaram que a introdução de leguminosas em sistemas de rotação de culturas contribui para a adição de N e C ao solo. Reis Junior et al. (2004) observaram que pastagens formadas por algumas espécies do gênero 
Brachiaria spp. poderiam beneficiar-se com o processo de FBN, com destaque para a bactéria diazotrófica Azospirillum amazonense.

Em relação aos teores de $\mathrm{C}$ e $\mathrm{N}$, nas frações recalcitrantes da matéria orgânica do solo, observouse que a substituição do PD pelo sistema ILP8 após 8 anos de implantação, aumentou o estoque de $C$ nas substâncias húmicas (C-SH) (Figura 2). Na camada de 0-10 cm, comparado aos demais sistemas de manejo, o ILP8 promoveu incremento no teor de $\mathrm{C}-\mathrm{SH}$ de 37 e $39 \%$, em comparação ao PD e ao ILP4, respectivamente, e não diferiu da $\mathrm{VN}$ e da PR. Nas demais profundidades, não foram encontradas diferenças significativas entre os sistemas de manejo e a vegetação nativa (Figura 2).

O estoque de C-SH na camada $0-30 \mathrm{~cm}$ no ILP8 foi superior em 19, 6 e $28 \mathrm{Mg} \mathrm{ha}^{-1}$ de $\mathrm{C}$ em relação ao PD, PR e ILP4, todavia, não diferiu da PR e VN (Figura 2). Assim, a utilização do sistema ILP ampliou o potencial de retenção de $\mathrm{C}$ atmosférico nas frações mais recalcitrantes, as quais são as mais abundantes e quimicamente reativas da matéria orgânica do solo. Este fato é um ponto positivo para este sistema de manejo, pois o potencial para sequestrar $\mathrm{C}$ do solo depende de sua capacidade de acumular $\mathrm{C}$ nas substâncias húmicas e do C protegido fisicamente pelos agregados (Grinhut et al., 2007). Nos teores de N-SH não houve diferença entre os sistemas de usos e manejo nas diferentes camadas de solo (Figura 2). No entanto, observou-se diminuição dos estoques de $\mathrm{N}$-SH em todos os sistemas de manejo comparados à VN, e que, independentemente do sistema de manejo, a maior parte do $\mathrm{N}$ total do solo encontrou-se na fração mais recalcitrante da MOS.

Na fração recalcitrante da MOS, houve predominância da fração humina (HUM), em comparação às frações ácidoshúmicos $(\mathrm{AH})$ e fúlvicos $(\mathrm{AF})$, independentemente dos sistemas de manejo e profundidades analisadas (Figura 3). Nos sistemas de uso e manejo do solo, a fração Hum representou, em média, contribuição de 45 a $74 \%$ do COT do solo. Segundo Grinhut et al. (2007), esta predominância da fração HUM está relacionada à sua insolubilidade e resistência à biodegradação, favorecida pela formação de complexos argilo-húmicos estáveis. A composição mineralógica predominante dos solos em estudos, compostos de óxidos e hidróxidos de $\mathrm{Fe}$ e Al, favorecem as interações organo-minerais, aumentam a proteção dos grupos funcionais de fácil decomposição da fração Hum e contribuem para elevar seu estoque de C (Dick et al., 2003, 2008).

Os teores de C na fração humina (C-HUM) do ILP de 8 anos apresentaram incremento de 22,8 e $23,5 \mathrm{~g} \mathrm{~kg}^{-1}$
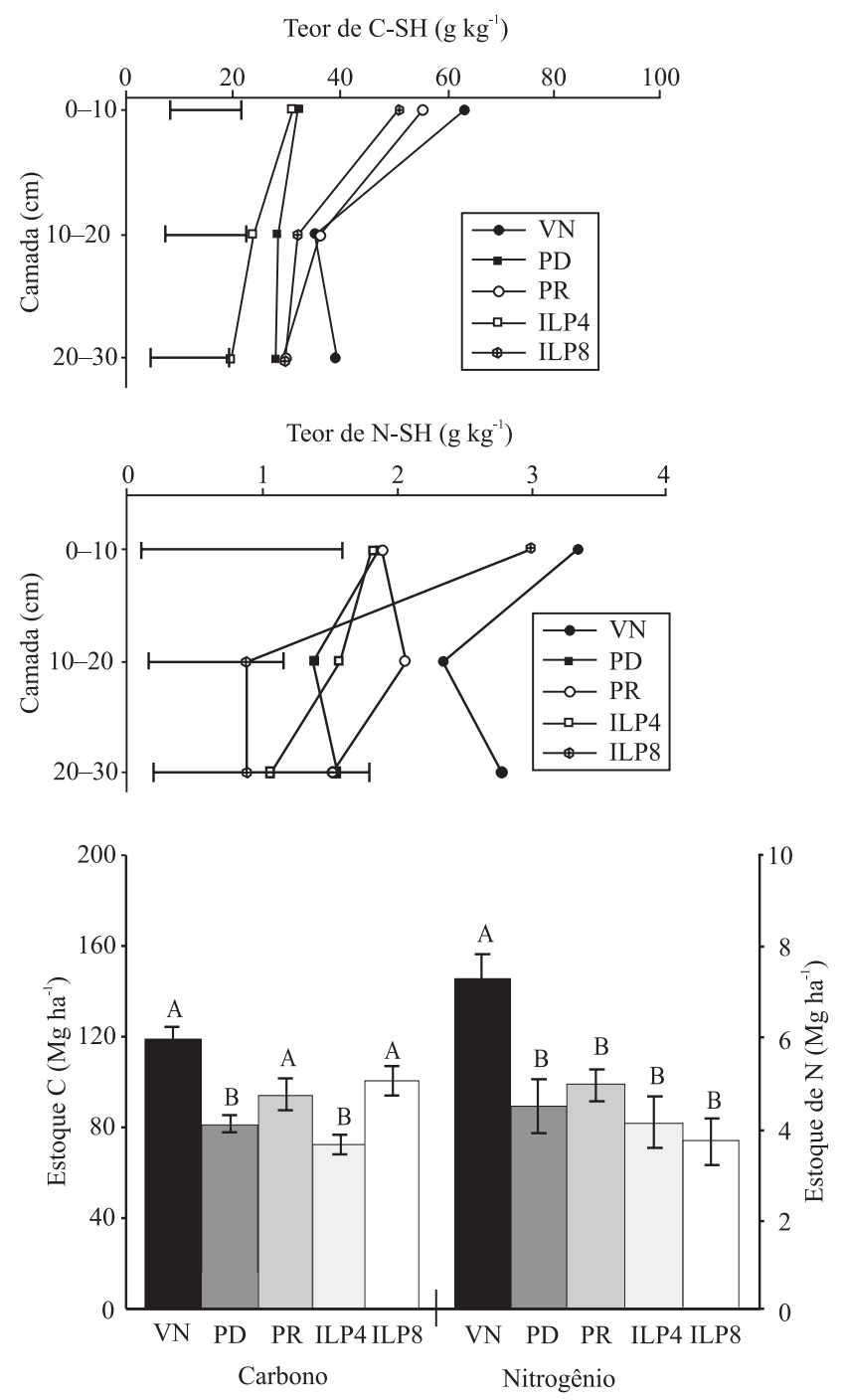

Figura 2. Teor de carbono e nitrogênio nas substâncias húmicas $(\mathrm{SH})$ da matéria orgânica do solo, em sistemas de manejo do solo, nas camadas $0-10,10-20$ e $20-30 \mathrm{~cm}$ de profundidade, e seus estoques na camada $0-30 \mathrm{~cm}$ do perfil do solo. VN, vegetação nativa; PD, plantio direto; PR, pastagem revolvida; ILP4 e ILP8, sistema de integração lavoura-pecuária, após quatro e oito anos de implantação. Médias seguidas de letras iguais não diferem entre si, pelo teste t, a $5 \%$ de probabilidade. Barras horizontais referem-se à DMS pelo teste $\mathrm{t}$, e barras verticais referem-se ao erropadrão da média. 

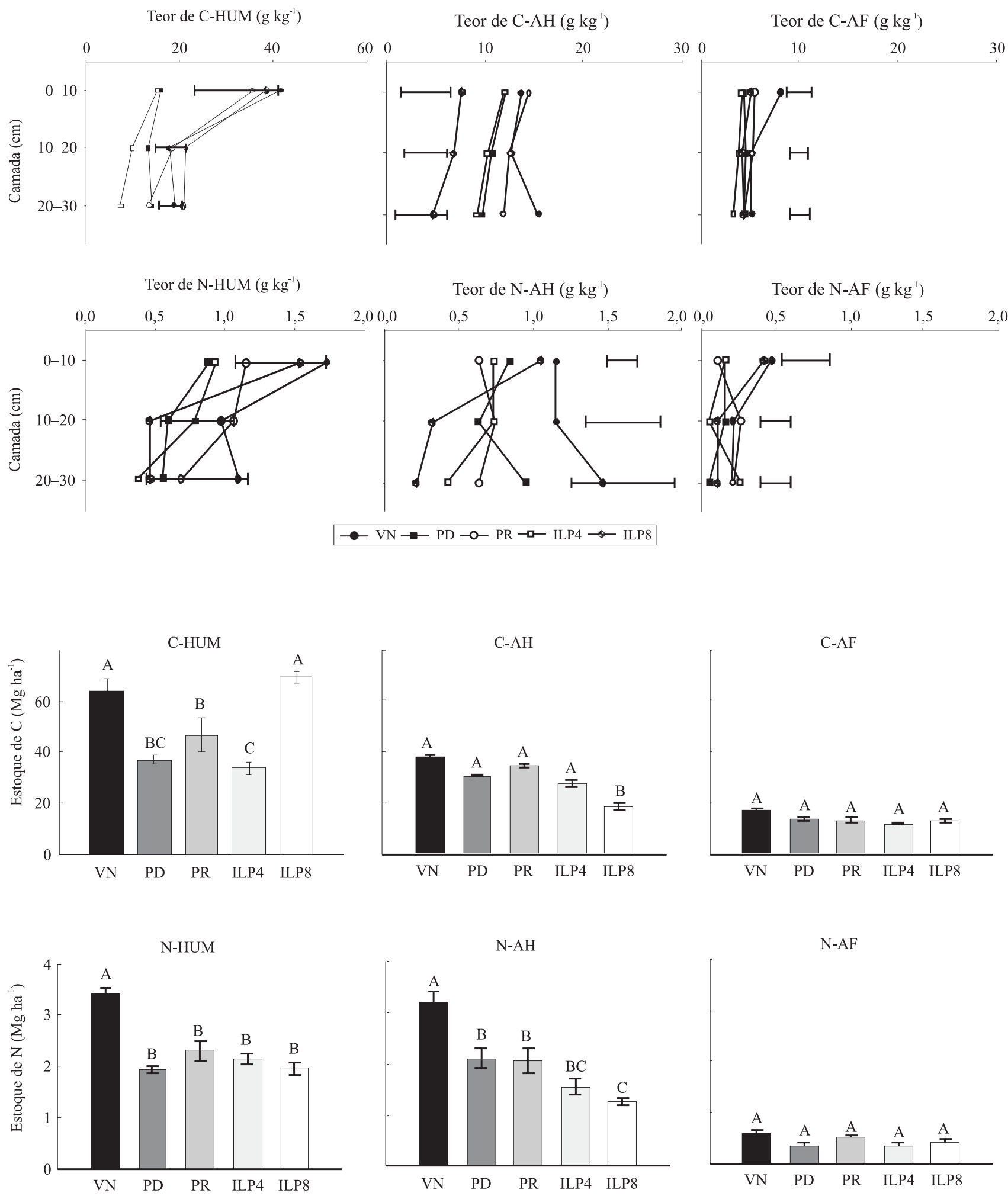

Figura 3. Teor de carbono e nitrogênio nas frações humina (HUM), ácido húmico (AH) e fúlvico (AF) em sistemas de manejo do solo, nas camadas 0-10, 10-20 e 20-30 cm de profundidade, e seus estoques na camada 0-30 cm do perfil do solo. VN, vegetação nativa; PD, plantio direto; PR, pastagem revolvida; ILP4 e ILP8, sistema de integração lavoura-pecuária, após quatro e oito anos de implantação. Médias seguidas de letras iguais não diferem entre si, pelo teste t a $5 \%$ de probabilidade. Barras horizontais referem-se à DMS pelo teste t e barras verticais referem-se ao erro-padrão da média. 
na camada de $0-10 \mathrm{~cm}, 8,1$ e $11,4 \mathrm{~g} \mathrm{~kg}^{-1}$ de $10-20 \mathrm{~cm}$, e 7,4 e 13,5 $\mathrm{g} \mathrm{kg}^{-1}$ de 20-30 cm, em comparação ao PD e ao ILP4, respectivamente. Na camada de $20-30 \mathrm{~cm}$, os teores de $\mathrm{C}$ na C-HUM também foram superiores aos da pastagem revolvida. $\mathrm{O}$ incremento no estoque do C-HUM do ILP8 foi de 32,1, 39,8 e 22,3 $\mathrm{Mg} \mathrm{ha}^{-1}$, em comparação ao do PD, ILP4 e PR, respectivamente, e não diferiu da VN (Figura 3). Todavia, observou-se redução nos teores de $\mathrm{C}$ na fração ácido húmico para ILP8, em comparação aos demais sistemas de manejo. Houve redução do estoque de C-AH de 32,1, 39,2 e 46,1\%, respectivamente, para ILP4, PD e PR. Com relação ao $\mathrm{C}$ na fração ácido fúlvico (C-AF), a redução no teor de $\mathrm{C}$ ocorreu apenas na camada de $0-10 \mathrm{~cm}$, e a $\mathrm{VN}$ foi superior aos demais sistemas de manejo, no entanto, os estoques de $\mathrm{C}$ no perfil foram semelhantes (Figura 3). A adição de $\mathrm{C}$ às substâncias húmicas $\mathrm{e}$ suas frações, principalmente no sistema ILP, pode ser atribuída à maior produção de resíduos vegetais com maior relação $\mathrm{C}: \mathrm{N}$ e lignina: $\mathrm{N}$, as quais possuem decomposição mais lenta do resíduo e favorecem o aumento de frações recalcitrantes no solo (Silva \& Mendonça, 2007). Outro fator seria a contribuição das raízes à estabilização da MOS (Rasse et al., 2005). Segundos esses autores, o $\mathrm{C}$ derivado de raízes tem um tempo médio de residência 2,4 vezes maior que o $\mathrm{C}$ derivado da parte aérea, e a contribuição das raízes para a MOS é cerca de $30 \%$ maior que a da parte aérea. Áreas de pastagens submetidas a boas práticas de manejo, às vezes, permitem a estocagem de COT e C nas frações lábeis e recalcitrantes no solo por período superior ao observado sob a vegetação nativa (Roscoe et al., 2006).

À semelhança do $\mathrm{C}$, a maior parte do $\mathrm{N}$ está associada à fração HUM, seguida das frações $\mathrm{AH}$ e AF. Nos sistemas de manejo, o acúmulo de N no ILP8 foi restrito à camada $0-10 \mathrm{~cm}$ do perfil, com aumento nos teores de $\mathrm{N}$ de 42 e $39 \%$, em comparação ao PD e ao ILP4 para a fração humina, e, 20,9, 39 e 29,8\% em comparação ao PD, PR e ILP4 para a fração AH, respectivamente (Figura 3). Não houve diferença nos teores de $\mathrm{N}$ na fração AF entre os sistemas. Os estoques de $\mathrm{N}$ na vegetação nativa foram superiores nas frações HUM e AH, em comparação a todos os sistemas de manejo, e semelhante na fração AF. O estoque de $\mathrm{N}$ no ILP8 na fração AH foi inferior ao dos sistemas PD e PR e semelhante ao do ILP4 (Figura 3).

As frações recalcitrantes que apresentam maiores teores de $\mathrm{N}$ são mais suscetíveis à biodegradação e podem ser uma fonte importante desse elemento para as plantas (Schulten \& Schnitzer, 1997). Entre os compostos orgânicos nitrogenados, identificados em maior proporção no solo, encontram-se os aminoácidos e os açúcares aminados. Além dessas formas, uma porção significativa do $\mathrm{N}$ do solo ocorre como componente estrutural dos ácidos húmicos (Schulten \& Schnitzer, 1997).

Os sistemas conservacionistas, com revolvimento do solo somente na linha de plantio, rotação de culturas, manutenção dos resíduos culturais na superfície do solo - o que proporciona decomposição lenta do material vegetal depositado - como o PD e o ILP, favoreceram o acúmulo de CL e NL e aumentaram o IMC.

Apesar de o teor de COT $(0-10 \mathrm{~cm})$ no sistema ILP com 8 anos de implantação apresentar redução significativa de $45 \%$, em comparação ao da vegetação nativa, houve queda nessa redução para $16 \%$ no teor de CL considerada não significativa (Figura 4). Esse comportamento ressalta a maior sensibilidade do CL em indicar incrementos na MOS por meio do cultivo, do que quando comparado somente com o estoque de COT. Dieckow et al. (2005) e Souza et al. (2009) observaram que os estoques de CL diminuíram rapidamente, porém sua recuperação também foi rápida, o que sugere o uso do CL como um indicador sensível da dinâmica do $\mathrm{C}$ no sistema. A manutenção dos estoques de $\mathrm{C}$ do solo, especialmente nas frações lábeis, é essencial à melhoria da qualidade do solo, formação e estabilização de agregados e sustentabilidade desses sistemas de produção (Blair \& Crocker, 2000).

De maneira análoga, Blair et al. (1995), ao avaliar solos da Austrália e do Brasil, constataram que o cultivo agrícola (trigo em rotação com leguminosas e cana-de-açúcar) resultou em maior redução do CL $(63,3 \%)$, em comparação àquelas observadas para o CNL $(39,3 \%)$ e o COT $(44,9 \%)$. Ao avaliar a dinâmica desses compartimentos, em Latossolo do Brasil, após 12 meses sob cobertura morta, em um experimento conduzido com cana-de-açúcar, esses mesmos autores observaram aumentos de 39,7, 2,4 e 8,5\% no CL, CNL e COT, respectivamente.

Com relação ao CL, as diferenças entre os sistemas de manejo ficaram restritas à camada superficial $(0-10 \mathrm{~cm})$. A adoção do PD por 23 anos e ILP8 com oito anos de implantação promoveu aumento no teor de CL de 16 e $27 \%$, em comparação ao PR e ILP4, respectivamente, e ambos os sistemas não se diferenciaram da VN. Na análise do estoque de CL na camada de $0-30 \mathrm{~cm}$, a utilização do 
sistema ILP por oito anos apresentou acréscimo de 19\% em relação ao de quatro anos (Figura 4).

Em relação ao PD, houve incremento de NL de $41 \mathrm{e}$ $52 \%$ na camada $0-10 \mathrm{~cm}$, para ILP de quatro e oito anos, respectivamente. O ILP com oito anos de implantação apresentou teores de NL semelhantes aos da vegetação nativa, nas camadas $0-10,10-20$ e $20-30 \mathrm{~cm}$. Na camada $10-20$ e $0-30 \mathrm{~cm}$ o ILP8 foi semelhante ao
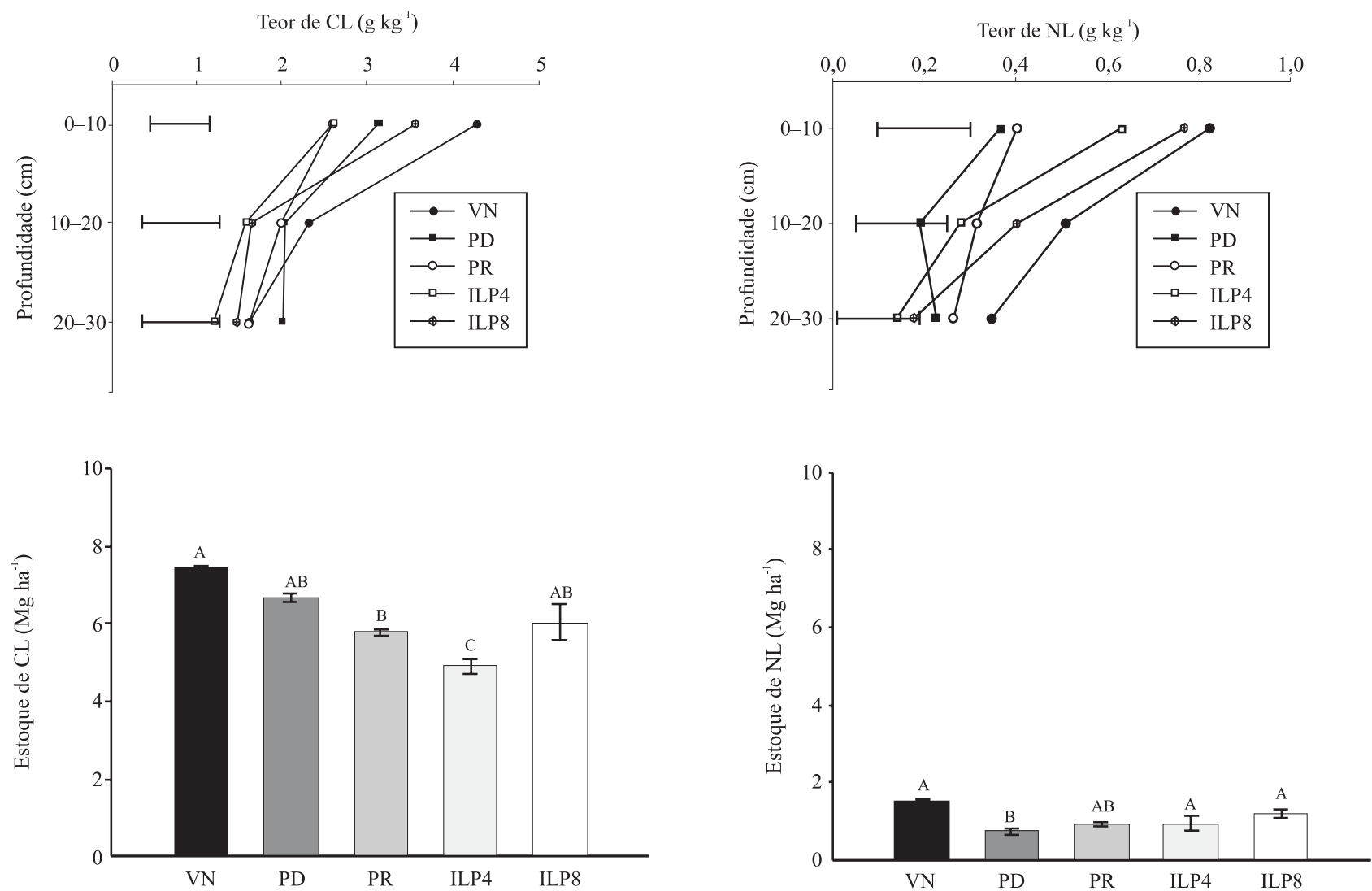

$0-10 \mathrm{~cm}$

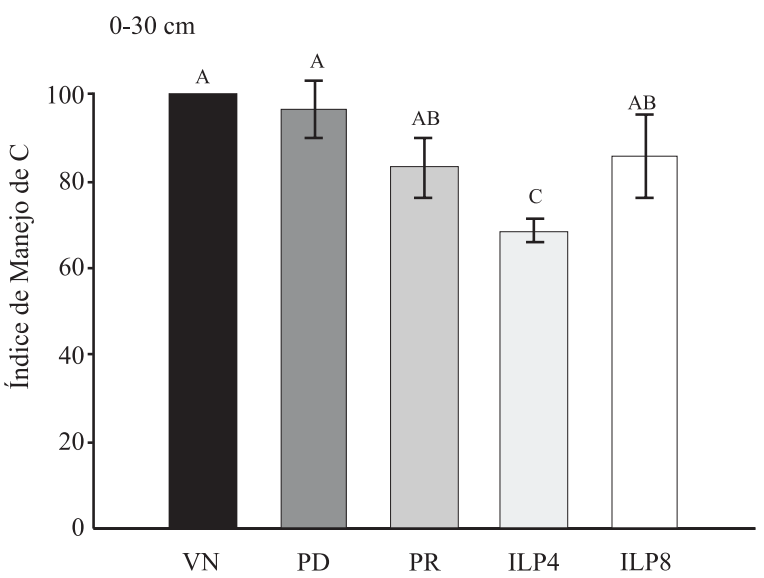

Figura 4. Teor de carbono (CL) e nitrogênio (NL) lábil e índice de manejo de carbono (IMC) em sistemas de manejo do solo, nas camadas $0-10,10-20$ e $20-30 \mathrm{~cm}$ de profundidade, e seus estoques na camada $0-30 \mathrm{~cm}$ do perfil do solo. VN, vegetação nativa; PD, plantio direto; PR, pastagem revolvida; ILP4 e ILP8, sistema de integração lavoura-pecuária, após quatro e oito anos de implantação. Médias seguidas de letra iguais não diferem entre si, pelo teste t a $5 \%$ de probabilidade. Barras horizontais referem-se à DMS pelo teste $t$ e barras verticais referem-se ao erro-padrão da média. 
sistema de referência, a VN (Figura 4). Para o estoque de NL, com exceção da pastagem revolvida, os sistemas de manejo que incluíram pastagem (ILP) foram superiores ao $\mathrm{PD}$ e foram semelhantes à vegetação nativa.

O IMC sugerido por Blair et al. (1995) leva em consideração aspectos da labilidade da MOS e permite comparar as mudanças que ocorrem no COT e CL em consequência do uso e manejo do solo. Para o ILP8 com oito anos de implantação, o índice obtido de 88 foi superior ao dos demais sistemas de manejo e não diferiu do sistema de referência $(\mathrm{VN})$ na camada de $0-10 \mathrm{~cm}$. Na análise do perfil, houve diluição desse efeito, ou seja, ILP8 (84) obteve valores significativamente similares ao PD (96) e ao PR (83) (Figura 4). Mas, quando comparado ao ILP4, o sistema integração lavourapecuária com oito anos promoveu aumento de $18 \%$ no IMC (Figura 4). O fato de os sistemas de manejo mais conservacionistas (PD e ILP8) apresentarem IMC superior ou significativamente igual ao sistema de referência $(\mathrm{VN}=100)$ evidencia a capacidade de melhorarem e promoverem a sustentabilidade do agroecossistema em regiões tropicais, pela manutenção de $\mathrm{C}$ no sistema agrícola.

Esses valores foram menores que os obtidos por Souza et al. (2009), que analisaram o IMC em ILP submetido a diferentes alturas de pastejo (10, 20 e $40 \mathrm{~cm}$ ), no Rio Grande do Sul, e observaram que a altura de pastejo de 40 e $20 \mathrm{~cm}$ e o IMC foram semelhantes (100 e 107), o que mostra que essas áreas têm mantido a labilidade da matéria orgânica de forma semelhante à da área de referência (sem pastejo), enquanto que, na maior intensidade de pastejo $(10 \mathrm{~cm})$ esse índice foi inferior (65), o que mostra o efeito da intensidade do pastejo. Dieckow et al. (2005) avaliaram um Argissolo submetido a diferentes sistemas de cultura e adubação nitrogenada sob PD, tendo utilizado como referência um campo nativo com índice 100 e observaram que, no sistema com maior aporte de resíduos ao solo, o IMC foi maior (256), enquanto o IMC no solo descoberto e no sistema aveia/milho sem $\mathrm{N}$ mineral este índice foi bem mais baixo, próximo de 56 .

\section{Conclusões}

1. A análise do carbono orgânico total é sensível para detectar diferenças entre os sistemas de manejo do solo, porém a magnitude dos efeitos é maior nas frações lábeis da matéria orgânica do solo.

2. O sistema de integração lavoura-pecuária após oito anos de implantação pode propiciar estoque de nitrogênio total semelhante ao do sistema sob vegetação nativa, além de mostrar incrementos nos estoques de carbono orgânico total e nas frações lábeis e recalcitrantes da matéria orgânica do solo.

3. A integração lavoura-pecuária estabelecida no período de oito anos é capaz de alcançar um novo estado estável, equivalente ao do sistema sob plantio direto com 23 anos de implantação.

\section{Agradecimentos}

À Fundação de Apoio ao Desenvolvimento do Ensino, Ciência e Tecnologia do Estado de Mato Grosso do Sul e ao Conselho Nacional de Desenvolvimento Científico e Tecnológico, pelo apoio financeiro e concessão de bolsa.

\section{Referências}

AYOADE, J.O. Introdução à climatologia para os trópicos. São Paulo: Difel, 1986. 332p.

BATLLE-BAYER, L.; BATJES, N.H.; BINDRABAN, P.S. Changes in organic carbon stocks upon land use conversion in the Brazilian Cerrado: a review. Agriculture, Ecosystems and Environment, v.137, p.47-58, 2010.

BAYER, C.; MIELNICZUK, J.; AMADO, T.J.C.; MARTIN NETO, L. Organic matter storage in a sandy clay loam Acrisol affected by tillage and cropping systems in Southern Brazil. Soil and Tillage Research, v.54, p.101-109, 2000.

BLAIR, G.J.; LEFROY, R.D.B.; LISLE, L. Soil carbon fractions based on their degree of oxidation, and the development of a carbon management index for agricultural systems. Australian Journal of Agricultural Research, v.46, p.1459-1466, 1995.

BLAIR, N.; CROCKER, G.J. Crop rotation effects on soil carbon and physical fertility of two Australian soils. Australian Journal Agriculture Research, v.38, p.71-84, 2000.

CERETTA, C.A.; BASSO, C.J.; FLECHA, A.M.T.; PAVINATO, P.S.; VIEIRA, F.C.B.; MAI, M.E.M. Manejo da adubação nitrogenada na sucessão aveia-preta/milho, no sistema plantio direto. Revista Brasileira de Ciência do Solo, v.26, p.163-171, 2002.

CIOTTA, M.N.; BAYER, C.; ERNANI, P.R.; FONTOURA, S.M.V.; ALBUQUERQUE, J.A.; WOBETO, C. Acidificação de Latossolo sob plantio direto. Revista Brasileira de Ciência do Solo, v.26, p.1055-1064, 2002.

CLAESSEN, M.E.C. (Org.). Manual de métodos de análises de solo. 2.ed. rev. atual. Rio de Janeiro: Embrapa Solos, 1997. 212p. 
CONCEIÇÃO, P.C.; AMADO, T.J.C.; MIELNICZUK, J.; SPAGNOLLO, E. Qualidade do solo em sistemas de manejo avaliada pela dinâmica da matéria orgânica e atributos relacionados. Revista Brasileira de Ciência do Solo, v.29, p.777-788, 2005.

D'ANDRÉA, A.F.; SILVA, M.L.N.; CURI, N.; GUILHERME, L.R.G. Estoque de carbono e nitrogênio e formas de nitrogênio mineral em um solo submetido a diferentes sistemas de manejo. Pesquisa Agropecuária Brasileira, v.39, p.179-186, 2004.

DICK, D.P.; SANTOS, J.H.Z.; FERRANTI, E.M. Chemical characterization and infrared spectroscopy of soil organic matter from two Southern Brazilian soils. Revista Brasileira de Ciência do Solo, v.27, p.29-39, 2003.

DICK, D.P.; SILVA, L.B.; INDA, A.V.; KNICKER, H. Estudo comparativo da matéria orgânica de diferentes classes de solos de altitude do Sul do Brasil por técnicas convencionais e espectroscópicas. Revista Brasileira de Ciência do Solo, v.32, p.2289-2296, 2008.

DIEKOW, J.; MIELNICZUK, J.; KNICKER, H.; BAYER, C.; DICK, D.P.; KÖGEL-KNABNER, I. Soil C and N stocks as affected by cropping systems and nitrogen fertilisation in a Southern Brazil Acrisol managed under no-tillage for 17 years. Soil and Tillage Research, v.81, p.87-95, 2005.

ELLERT, B.H.; BETTANY, J.R. Calculation of organic matter and nutrients stored in soils under contrasting management regimes. Canadian Journal of Soil Science, v.75, p.529-538, 1995.

GRINHUT, T.; HADAR, Y.; CHEN, Y. Degradation and transformation of humic substances by saprotrophic fungi: processes and mechanisms. Fungal Biology Reviews, v.21, p.179-189, 2007.

HART, S.C.; NASON, G.E.; MYROLD, D.D.; PERRY, D.A. Dynamics of gross nitrogen transformations in an old-growth forest: the carbon connection. Ecology, v.75, p.880-891, 1994.

LOSS, A.; PEREIRA, M.G.; SCHULTZ, N.; ANJOS, L.H.C. dos; SILVA, E.M.R. Carbono e frações granulométricas da matéria orgânica do solo sob sistemas de produção orgânica. Ciência Rural, v.39, p.1067-1072, 2009.

LOVATO, T.; MIELNICZUK, J.; BAYER, C.; VEZZANI, F. Adição de carbono e nitrogênio e sua relação com os estoques no solo e com o rendimento do milho em sistemas de manejo. Revista Brasileira de Ciência do Solo, v.28, p.175-187, 2004.

NICOLOSO, R. S.; LOVATO, T.; AMADO, T.J.C.; BAYER, C.; LANZANOVA, M.E. Balanço do carbono orgânico no solo sob integração lavoura-pecuária no Sul do Brasil. Revista Brasileira de Ciência do Solo, v.32, p.2425-2433, 2008.

RASSE, D.P.; RUMPEL, C.; DIGNAC, M.F. Is soil carbon mostly root carbon? Mechanisms for a specific stabilisation. Plant and Soil, v.269, p.341-356, 2005.

REIS JUNIOR, F.B. dos; SILVA, M.F. da; TEIXEIRA, K.R.S.; URQUIAGA, S.; REIS, V.M. Intra-specific diversity study of the nitrogen fixing bacterium Azospirillum amazonense isolated from different Brachiaria species. Symbiosis, v.36, p.41-56, 2004.

ROSCOE, R.; BODDEY, R.M.; SALTON, J.C. Sistemas de manejo e matéria orgânica do solo. In: ROSCOE, R.; MERCANTE, F.M.; SALTON, J.C. (Ed.). Dinâmica da matéria orgânica do solo em sistemas conservacionistas: modelagem matemática e métodos auxiliares. Dourados: Embrapa Agropecuária Oeste, 2006. 304p.

ROSCOE, R.; BUURMAN, P. Tillage effects on soil organic matter in density fractions of a Cerrado Oxisol. Soil and Tillage Research, v.70, p.107-119, 2003.

ROSSI, C.Q. Dinâmica da matéria orgânica do solo em área de soja cultivada sobre palhada de braquiária e sorgo. 2009. 72p. Tese (Doutorado) - Universidade Federal Rural do Rio de Janeiro, Seropédica.

SANTOS, H.P. dos; FONTANELI, R.S.; SPERA, S.T.; TOMM, G.O. Efeito de sistemas de produção integração lavoura-pecuária (ILP) sobre a fertilidade do solo em plantio direto. Acta Scientiarum. Agronomy, v.31, p.719-727, 2009.

SCHULTEN, H.R.; SCHNITZER, M. Chemical model structures for soil organic matter and soils. Soil Science, v.162, p.115-130, 1997.

SHANG, C.; TIESSEN, H. Organic matter lability in tropical Oxisol: evidence from shifting cultivation, chemical oxidation, particle size, density, and magnetic fractionations. Soil Science, v.162, p.795-807, 1997.

SILVA, I.R.; MENDONÇA, E.S. Matéria orgânica do solo. In: NOVAIS, R.F.; ALVAREZ V., V.H.; BARROS, N.F.; FONTES, R.L.F.; CANTARUTTI, R.B.; NEVES, J.C.L. (Ed.). Fertilidade do solo. Viçosa: Sociedade Brasileira de Ciência do Solo, 2007. $1017 \mathrm{p}$.

SISTI, C.P.J.; SANTOS, H.P. dos; KOHHANN, R.; ALVES, B.J.R.; URQUIAGA, S.; BODDEY, R.M. Change in carbon and nitrogen stocks in soil under 13 years of conventional or zero tillage in Southern Brazil. Soil and Tillage Research, v.76, p.39-58, 2004.

SOUZA, E.D. de; COSTA, S.E.V.G. de A.; ANGHINONI, I.; CARVALHO, P.C. de F.; ANDRIGUETI, M.; CAIO, E. Estoque de carbono orgânico e de nitrogênio no solo em sistema de integração lavoura-pecuária em plantio direto, submetido a intensidades de pastejo. Revista Brasileira de Ciência do Solo, v.33, p.1829-1836, 2009.

SWIFT, R.S. Sequestration of carbon by soil. Soil Science, v.166, p.858-871, 2001.

VIEIRA, F.C.B.; BAYER, C.; ZANATTA, J.A.; DIECKOW, J.; MIELNICZUK, J.; HE, Z.L. Carbon management index based on physical fractionation of soil organic matter in an Acrisol under long-term no-till cropping systems. Soil and Tillage Research, v.96, p.195-204, 2007.

YEOMANS, J.C.; BREMNER, J.M. A rapid and precise method for routine determination of organic carbon in soil. Communications in Soil Science and Plant Analysis, v.19, p.1467-1476, 1988.

Recebido em 30 de julho de 2010 e aprovado em 17 de agosto de 2011 